\title{
Medium Formulation and its optimization for increased protease production by Penicillium sp. LCJ228 and its potential in blood stain removal
}

\author{
V. Benluvankar ${ }^{1}$, S. Evelyne Priya ${ }^{2}$, J. Joel Gnanadoss ${ }^{1 *}$ \\ ${ }^{1}$ Microbial and Environmental Biotechnology Research Unit Department of Plant Biology and Biotechnology Loyola College (Autonomous), Chennai - 600 \\ 034, India. ${ }^{2}$ Department of Plant Biology and Plant Biotechnology Ethiraj College for Women (Autonomous), Chennai - 600008 , India.
}

\section{ARTICLE INFO}

Article history:

Received on: 25/09/2015

Revised on: 17/10/2015

Accepted on: 01/12/2015

Available online: 08/01/2016

Key words:

Protease, Penicillium sp.,

submerged fermentation,

conventional optimization,

blood stain removal.

\begin{abstract}
The production of protease by Penicillium sp. LCJ228 was optimized under submerged fermentation. Nutritional and physical factors that influence protease production were optimized by one factor at a time (OFAT) method in order to achieve high yield of protease. Maximum protease production was obtained on the $4^{\text {th }}$ day in a liquid medium containing glucose $(15 \mathrm{~g} / \mathrm{L})$, yeast extract $(15 \mathrm{~g} / \mathrm{L})$, black gram husk $(10 \mathrm{~g} / \mathrm{L})$ with an initial $\mathrm{pH}$ of 10 and an inoculum size of $2 \mathrm{~g} / \mathrm{L}$ of fungal mycelium. About 2.4 fold increase in protease production was observed in the optimized medium. The maximally yielded crude protease was then precipitated and characterized by SDSPAGE and native-PAGE. The molecular weight of the ammonium sulphate precipitated protease was $\sim 66$ to 70 $\mathrm{kDa}$ and native-PAGE showed three isoenzymes. The crude and precipitated protease had the ability to completely remove blood stains on cotton fabric indicating its potential to be used as a stain remover in detergents.
\end{abstract}

\section{INTRODUCTION}

Proteases are the most significant group of the industrial enzymes that execute a wide variety of functions and are commercially used for various industrial purposes [1, 2]. They have widespread applications in detergents, food, pharmaceuticals and leather industries [3, 4]. Proteases account for about $60 \%$ of the total enzyme market in the worldwide enzyme sale [5]. Increasing demand of proteases had lead researchers to search promising sources of proteases $[6,7]$. Proteases are generally synthesized and produced by numerous microorganisms which include bacteria, fungi and actinomycetes $[8,9]$. There are many microbial sources accessible for protease production, only a few are considered as commercial producers [10]. Among them, fungi are well known sources of extracellular enzymes. Protease production by fungi belonging to genera Aspergillus [11, 12, 13], Rhizopus [14], Mucor [13] and Penicillium [15, 16, 17] have been studied extensively. Extracellular proteases from fungi can be produced by both submerged fermentation $(\mathrm{SmF}) \&$ solid state fermentation (SSF).

\footnotetext{
* Corresponding Author

Joel Gnanadoss J, Microbial and Environmental Biotechnology Research Unit Department of Plant Biology and Biotechnology Loyola College (Autonomous), Chennai - 600 034, India.

Email: joelgna@gmail.com
}

The growth medium used in SmF is generally optimized using the one-variable-at-a-time method. In this method all variables except one are kept constant, while the optimum level of the testing variable is determined. There is no single defined medium for the optimum protease production from microorganisms as every organism has its own special conditions for maximum enzyme production [18].

To establish a successful fermentation process for protease production, it is essential to optimize the media components such as carbon, nitrogen and inducer source and physical factors such as inoculum size, $\mathrm{pH}$, temperature, aeration and growth time [16].

Microbial alkaline proteases dominate commercial applications with a significant share of about $25 \%$ of the total worldwide sales of enzymes for laundry detergent applications. Protease based detergent preparations enables the removal of proteinaceous material from the stains and improves washing effectively with in a shorter duration [19]. The first detergent containing the bacterial enzyme was introduced in 1956 under the trade name BIO-40. Currently, many commercial detergent produces used in the market are serine proteases produced by Bacillus strains. However, fungal alkaline proteases are advantageous due to the ease of downstream processing to prepare a microbe-free enzyme [20]. Recently, there has been increasing research about utilization of fungal proteases in detergent industry. However, only a few fungal strains are exploited commercially. 
The present study is aimed to optimize suitable medium and culture conditions for extracellular protease production by Penicillium sp. LCJ228 under submerged fermentation and removal of blood stains from the cotton fabric using partially purified protease.

\section{MATERIALS AND METHODS}

\subsection{Organism and culture maintenance}

The mould Penicillium sp. LCJ228 was isolated from soil samples using Potato Dextrose Agar (PDA) plates. The culture was screened for protease activity based on the hydrolysis on the skimmed milk agar medium. The culture was maintained on PDA slants and was stored at $4{ }^{\circ} \mathrm{C}$.

\subsection{Fermentation medium and culture conditions}

Production of protease by submerged fermentation was studied in five different basal medium. Medium 1 Sarker et al., 2013) [21] g/L : Glucose, 10; Peptone, 10; K2HPO4, 1; MgSO4, 0.2; Na2CO3, 5; Medium 2 [19] g/L : Glucose, 2; Yeast extract, 1; K2HPO4, 0.1; KH2PO4, 0.1; Casein, 1.5; Medium 3 [22] g/L: Glucose, 10; Gelatin, 10; K2HPO4, 1; MgSO4, 0.5; Medium 4 [23] g/L: Glucose, 10; Casein, 5; Yeast extract, 5; MgSO4, 0.2; K2HPO4, 1; Na2CO3, 10; Medium 5 [24] g/L: Yeast extract, 5; Peptone, 5; Glucose, 10; Casein, 20. About $100 \mathrm{~mL}$ of medium was dispensed into $250 \mathrm{~mL}$ conical flask and autoclaved at $121^{\circ} \mathrm{C}$ for 15 mins.

A pinch of nalidixic acid was added to avoid bacterial growth. One mycelial disc was inoculated into the conical flask, under sterile condition and incubated on a rotary shaker at 120 rpm. $10 \mathrm{~mL}$ of the culture filtrate was taken every $48 \mathrm{hrs}$ and centrifuged at 10,000 rpm for 10 mins. The supernatant was used as a crude enzyme solution for protease activity.

\subsection{Time course of protease production}

The growth curve was obtained by inoculating culture in $250 \mathrm{~mL}$ Erlenmeyer flasks containing $100 \mathrm{~mL}$ of production medium. The flasks for each sampling were incubated on a rotary shaker at $120 \mathrm{rpm}$. The experiment was designed for 10 days starting from the lag phase to stationary phase.

\subsection{Optimization of fermentation conditions}

Under submerged fermentation, nutritional factors such as different carbon sources namely glucose, sucrose, fructose, maltose, starch and lactose, different nitrogen sources namely peptone, yeast extract, ammonium chloride, sodium nitrate and different inducer sources including casein, groundnut oilcake, mahua oilcake, black gram husk and red gram husk were studied. The effect of their concentration ranging for 5 to $30 \mathrm{~g} / \mathrm{L}$, influencing the production of protease was optimized by incorporating one-factor-at-a-time method. Similarly, the influence of $\mathrm{pH}$ (4 to 9 ), inoculum size ( 1 to $5 \mathrm{~g} / \mathrm{L}$ ), static and shaking conditions were also studied.

\subsection{Protease assay}

Protease activity was determined spectrophotometrically by using casein as substrate. $500 \mu \mathrm{L}$ of $0.5 \%(\mathrm{w} / \mathrm{v})$ of casein $(\mathrm{pH}$ 7) in $0.2 \mathrm{M}$ phosphate buffer of $300 \mu \mathrm{L}(\mathrm{pH} \mathrm{7)}$ and $200 \mu \mathrm{L}$ crude enzyme extract were mixed together and incubated at room temperature for 10 mins. After incubation, the enzyme reaction was terminated by the addition of $1 \mathrm{~mL}$ of $5 \%(\mathrm{w} / \mathrm{v})$ trichloroacetic acid (TCA) [25]. The reaction mixture was then centrifuged to separate the unreacted casein at $10,000 \mathrm{rpm}$ for 15 minutes. To $1 \mathrm{~mL}$ of supernatant, $5 \mathrm{~mL}$ of $0.4 \mathrm{M} \mathrm{Na} 2 \mathrm{CO} 3$ and 1 $\mathrm{mL}$ of 3 -fold diluted Folin Ciocalteu's reagent were added and mixed well. The resulting solution was incubated in the dark for 30 mins at room temperature and absorbance was measured at 660 $\mathrm{nm}$. The protein content was estimated by following the method described by Lowry et al., [26] using bovine serum albumin as the standard.

\subsection{Partial purification of protease}

The cell-free culture filtrate of Penicillium sp. culture was collected by centrifugation after 4 days of growth. The extracellular enzyme was precipitated by the addition of ammonium sulphate $(70 \%)$ to saturation. The mixture was incubated overnight at $4{ }^{\circ} \mathrm{C}$ and separated by centrifugation at $10,000 \mathrm{rpm}$ for $30 \mathrm{mins}$.

\subsection{Enzyme characterization}

Molecular weight of the protease was determined by Sodium dodecyl sulphate - polyacrylamide gel electrophoresis (SDS - PAGE). After electrophoresis, the gel was stained with CBB R250 and protein bands were visualized under an illuminator.

For zymography, $0.5 \%(\mathrm{w} / \mathrm{v})$ gelatin was co-polymerized with the running gel and samples were then loaded onto the gel without heating followed by electrophoresis with $100 \mathrm{~V}$ at room temperature. Following electrophoresis, the gel was incubated in $2.5 \%(\mathrm{v} / \mathrm{v})$ Triton X-100 (renaturing solution) for $30 \mathrm{mins}$ at room temperature with gentle agitation, then was decanted and replaced with developing buffer $(50 \mathrm{mM}$ Tris, $0.2 \mathrm{mM} \mathrm{NaCl}$, and $5 \mathrm{mM}$ $\mathrm{CaCl} 2, \mathrm{pH}$ 8.0) and incubated at $37^{\circ} \mathrm{C}$ for at least $20 \mathrm{hrs}$. The gel was stained with Coomassie Brilliant Blue G-250 in $0.5 \%(\mathrm{w} / \mathrm{v})$ for 30 mins and the band was observed under illuminator.

\subsection{Destaining of blood stains}

The efficiency of the protease to remove blood stains was analyzed by the stain removal test. Three pieces of uniform sized cotton fabric were stained with goat blood, dried at room temperature and fixed with $1 \%(\mathrm{v} / \mathrm{v})$ formaldehyde. The stained fixed fabrics were immersed separately in the crude enzyme, commercial detergent and precipitated protease for different time intervals ranging from 10 to $120 \mathrm{mins}$ at room temperature and examined for stain removal. The same procedure was followed for the control without the enzyme and detergent. 


\subsection{Statistical analysis}

The statistical method used in this study was the analysis of variance (ANOVA) using the software SPSS 11.5 and all data are results of duplicate experiments.

\section{RESULTS AND DISCUSSION}

Fungal proteases have several advantages over those produced from other sources and it also find applications in many industries. Proteases production is an inherent capacity of all fungal isolates, however only those species that produce substantial yield of extracellular proteases are considered to be industrial important [27]. Due to its vast applications, promising protease producing fungi are to be screened for the production of protease having desirable properties. Protease producing fungi showed clear zone of casein hydrolysis on skimmed milk agar [28], which was taken as the basis of screening in the present study. The preliminary screening revealed that Penicillium sp. LCJ228 was the most potent protease producer as it showed highest radius of hydrolysis zone. Similarly, there are earlier reports on protease production by Penicillium sp. [17,29,30].

Under submerged fermentation, media components for maximum protease production have been found to be different for each species. Therefore, the required chemical constituents and their concentrations have to be optimized accordingly [31]. In the present study, the production of protease by Penicillium sp. LCJ228 was carried out using five different media. Significant variations in biomass and protease activity were observed with different media tested. Initiation of fungal growth was observed after the 2nd day of inoculation. Among the five media tested, Medium 1 favoured maximum protease production with 134.2 $\mathrm{U} / \mathrm{mL}$ of protease activity on the 4 th day (Figure 1).

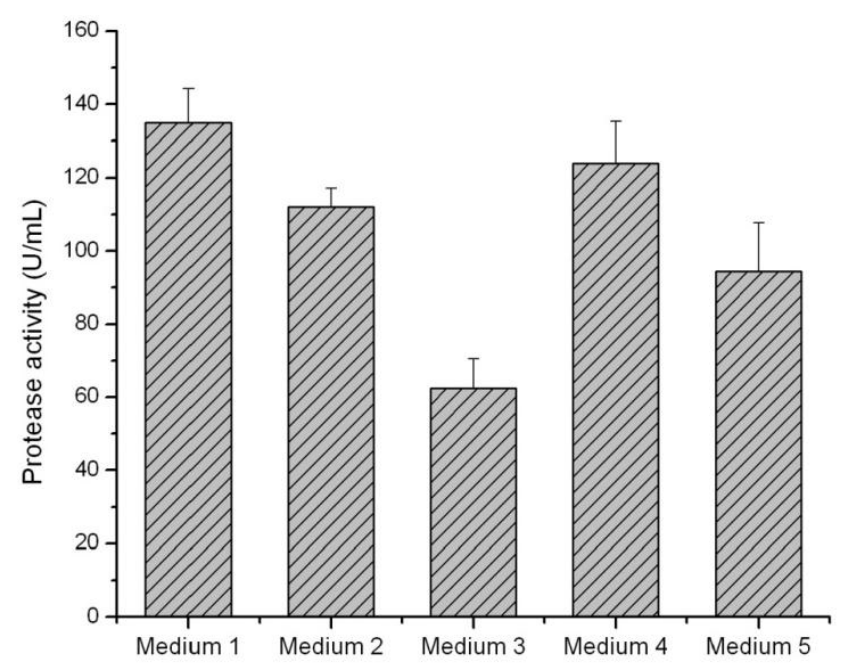

Fig. 1: Effect of different culture media on protease production by Penicillium sp. LCJ 228 on the $4^{\text {th }}$ day.

The growth pattern and protease production by Penicillium sp. LCJ228 was studied and results are presented in Figure 2 . The protease activity was the maximum on the 4 th day and increase in biomass was observed on the 6th day. After 6th day, a decline in protease activity was observed with increased in time biomass. Earlier it was reported that increased incubation time and declined protease activity may due to the depletion of nutrients in the production medium [32]. This could be due to altered physiology resulting in the inactivation of secretary machinery of the enzymes. In previous studies, maximum protease production by fungal cultures was reported on 4th to 9th day of incubation [12,33].

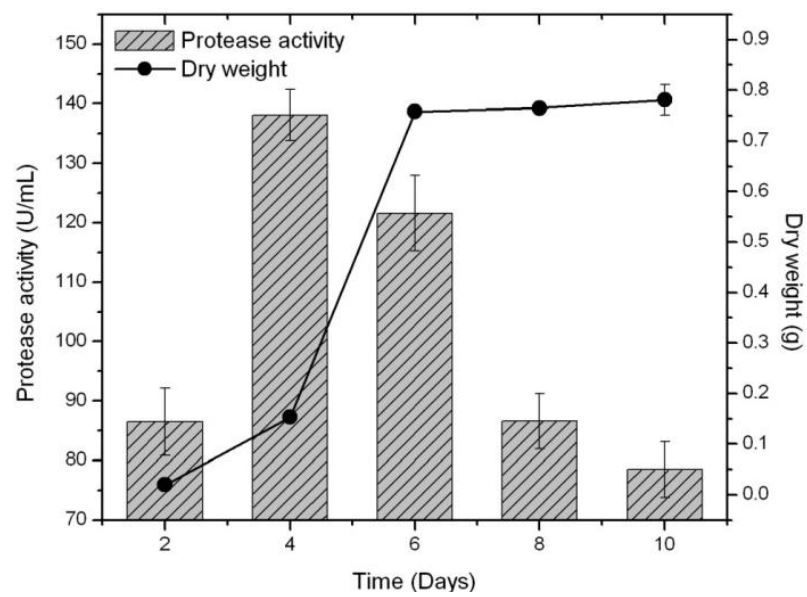

Fig. 2: Growth curve and protease production by Penicillium sp. LCJ228 in Medium 1

Several strategies have been adopted for the optimization of both physical factors as well as media components. In the present study one-factor-at-a-time method was employed for the optimization of protease production under submerged fermentation. Extracellular protease production in microorganisms is strongly influenced by medium components, e.g. variation in carbon and nitrogen ration, presence of easily metabolizable sugar, such as glucose [10] and metal ions [34]. It has also been reported that the optimization of medium components is carried out to maintain a balance between the different medium components and thus minimizes the amount of unutilized components at the end of the fermentation process [35].

In the present study, the ability of Penicillium sp. LCJ228 grown using various carbon sources indicated their specific utilization by the fungus. Among the mono-, di- and polysaccharides used in this study, glucose was the best carbon source for maximum protease production with $130.8 \mathrm{U} / \mathrm{mL}$ of protease activity at $5 \%$ level of significance (Table 1). This may be due to the reason that glucose is a monosaccharide and it is readily available for the metabolism of the fungus for enzyme production. Fructose and glucose proved to be the best carbon sources for improving the productivity of protease by Aspergillus flavus and Aspergillus terrus [36]. Similar results were also observed by Srinubabu et al.,[37] and Tremacoldi and Carmona [38]. It has also suggested that different carbon sources have different influences on extracellular enzyme production by different strains $[39,40]$. 
Table 1: Effect of different carbon and nitrogen sources on the protease production by Penicillium sp. LCJ 228 on the $4^{\text {th }}$ day.

\begin{tabular}{|c|c|}
\hline Factors & Protease activity $(\mathrm{U} / \mathrm{mL})$ \\
\hline \multicolumn{2}{|c|}{ Carbon source $(10 \mathrm{~g} / \mathrm{L})$} \\
\hline Starch & $61.2 \pm 1.09$ \\
\hline Fructose & $120.2 \pm 1.75$ \\
\hline Lactose & $100.0 \pm 3.87$ \\
\hline Maltose & $104.0 \pm 4.01$ \\
\hline Glucose & $130.8 \pm 2.47$ \\
\hline Sucrose & $43.6 \pm 1.92$ \\
\hline \multicolumn{2}{|c|}{ Nitrogen source $(10 \mathrm{~g} / \mathrm{L})$} \\
\hline Yeast extract & $250.2 \pm 4.94$ \\
\hline Peptone & $204.8 \pm 6.82$ \\
\hline $\mathrm{NH}_{4} \mathrm{Cl}_{2}$ & $34.4 \pm 1.76$ \\
\hline $\mathrm{Na}_{2} \mathrm{NO}_{3}$ & $154.6 \pm 3.32$ \\
\hline
\end{tabular}

The effect of glucose concentration showed that $20 \mathrm{~g} / \mathrm{L}$ of glucose enhanced maximum protease activity $(156 \mathrm{U} / \mathrm{mL})$ at $5 \%$ level of significance and declined beyond optimum concentration (Table 2). This decreased protease production at higher concentration of glucose may be due to the repression exerted by excessive amount of metabolizable sugar in enzyme production.

Table 2: Effect of concentrations of glucose and concentrations of yeast extract on the protease production by Penicillium sp. LCJ228 on the $4^{\text {th }}$ day.

\begin{tabular}{lc}
\hline Factors & Protease activity $(\mathbf{U} / \mathbf{m L})$ \\
\hline Glucose concentration $(\mathbf{g} / \mathbf{L})$ & $111.8 \pm 5.17$ \\
\hline 5 & $139.2 \pm 2.23$ \\
10 & $158.8 \pm 3.19$ \\
20 & $156.8 \pm 9.12$ \\
25 & $146.6 \pm 2.98$ \\
30 & $141.2 \pm 3.21$ \\
\hline Yeast extract concentration $\mathbf{( g / L )}$ & \\
\hline 5 & $209.2 \pm 6.09$ \\
10 & $210.2 \pm 3.12$ \\
15 & $280.8 \pm 1.56$ \\
20 & $238.0 \pm 9.12$ \\
25 & $248.6 \pm 11.0$ \\
30 & $237.2 \pm 5.95$ \\
\hline
\end{tabular}

Effect of different nitrogen sources and their concentration on the production of protease by Penicillium sp. LCJ228 was studied using different organic (peptone and yeast extract) and inorganic nitrogen sources (ammonium chloride, ammonium nitrate). The results showed that the growth and protease secretion was the maximum with organic nitrogen sources. Addition of yeast extract to the medium significantly $(\mathrm{p}<0.05)$ enhanced maximum protease production with 250.2 $\mathrm{U} / \mathrm{mL}$ of protease activity (Table 1 ). Similar observation was also made earlier where organic nitrogen sources were found to be effective than inorganic nitrogen sources for protease production [41]. Gnanadoss and Devi [17] suggested that organic nutrients are less expensive and also supply necessary minerals and vitamins required for protease production. It was also proved that yeast extract is a suitable nitrogen source which stimulates protease production in Aspergillus terreus [42]. The production of protease possibly was enhanced due to the high protein and amino acid components in the yeast extract.

The effect of different concentrations of yeast extract was also studied and results showed that $15 \mathrm{~g} / \mathrm{L}$ of yeast extract enhanced maximum protease production $(280.8 \mathrm{U} / \mathrm{mL})$ at $5 \%$ level of significance (Table 2). The inhibitory effect of yeast extract on the protease production was observed with an increasing concentration and this may be due to nitrogen metabolite repression.

Casein is one of the best chemical inducer for maximize the production of protease. In the present study, the production of protease by Penicillium sp. LCJ228 was optimized using both chemical and natural inducer. On the 4th day of incubation, $5 \mathrm{~g} / \mathrm{L}$ of casein (chemical inducer) showed maximum protease production with $220.1 \mathrm{U} / \mathrm{mL}$. In contrast, addition of powdered black gram husk (natural inducer) to the medium showed maximum $(243.4 \mathrm{U} / \mathrm{mL})$ protease activity and this was statistically significant at $5 \%$ level (Table 3 ). The yield of protease with addition of black gram husk powder to the medium was higher than casein amended medium. Higher protein content of the black gram husk could have possibly induced protease production by Penicillium sp. LCJ228. Kirankumar et al., [43] also reported that black gram husk significantly induced the production of protease by Trichoderma viridiae. Similar observation was also reported earlier where agricultural wastes could be used as the natural inducers for protease production which can reduce the cost of the medium [44].

Table 3: Effect of inducers on the protease production by Penicillium sp. LCJ 228 on the $4^{\text {th }}$ day.

\begin{tabular}{lc}
\hline Inducer & Protease activity $(\mathbf{U} / \mathbf{m L})$ \\
\hline Without inducer & $129.8 \pm 5.09$ \\
Casein & $220.1 \pm 7.01$ \\
Groundnut oilcake & $156.8 \pm 2.87$ \\
Mahua oilcake & $172.4 \pm 9.13$ \\
Red gram husk & $177.0 \pm 10.0$ \\
Black gram husk & $243.4 \pm 5.28$ \\
\hline
\end{tabular}

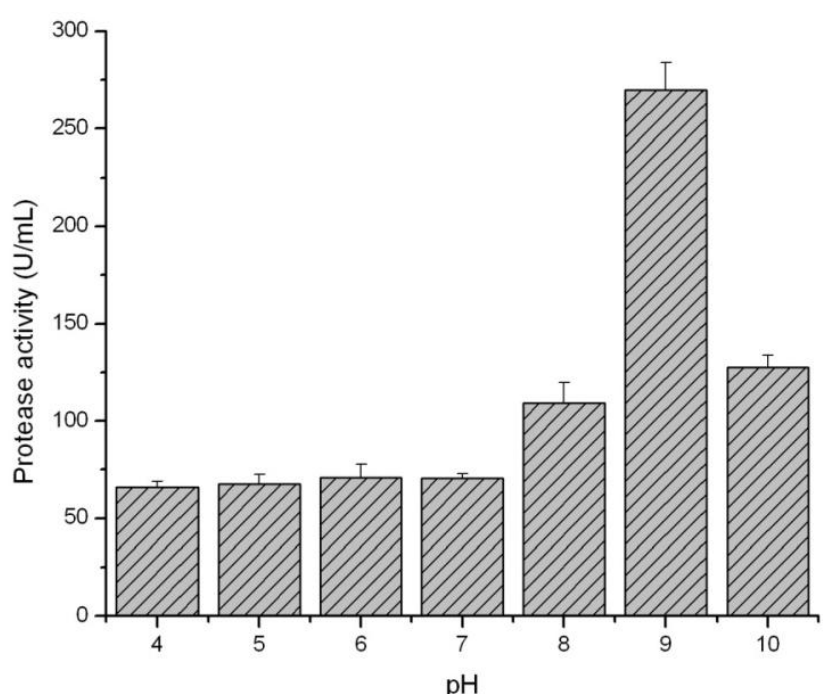

Fig. 3: Effect of different medium $\mathrm{pH}$ on the protease production by Penicillium sp. LCJ228 on the $4^{\text {th }}$ day.

Enzyme production by the fungal culture is strongly dependent on the medium $\mathrm{pH}$. It influences most of the enzymatic processes and the transport process of diverse of components across cell membrane $[45,46]$. In the present study, $\mathrm{pH} 9$ (alkaline 
$\mathrm{pH}$ ) favoured maximum protease production by Penicillium sp. LCJ228 with $269.8 \mathrm{U} / \mathrm{mL}$ of protease activity at $5 \%$ level (Figure 3). Similar results were also reported by Palanivel et al.,(2013) in Aspergillus strain KH17 [47]. It has also been reported that fungal proteases are active at neutral $\mathrm{pH}$ and alkaline $\mathrm{pH}$ around $\mathrm{pH} 7$ to $\mathrm{pH} 11$ [48].

Inoculum size also plays an important role in protease production. In the present investigation, the effect of inoculum size on the production of protease by Penicillium sp. LCJ228 was studied. $2 \mathrm{~g} / \mathrm{L}$ inoculum size significantly $(\mathrm{p}<0.05)$ enhanced maximum protease production with $256.6 \mathrm{U} / \mathrm{mL}$ of protease activity (Table 4). It was observed that protease activity decreased with as the inoculum size increased. It was earlier reported that the decline in enzyme production with high inoculum size was related to high biomass which is responsible for the reduction of the enzyme [49]. Similarly, lower protease production at lower inoculum size is probably due to less biomass which is insufficient to utilize the production medium for maximum protease production.

Table 4: Effect of inoculum size on the protease production by Penicillium sp. LCJ228 on the $4^{\text {th }}$ day.

\begin{tabular}{lc}
\hline Factors & Protease activity $(\mathbf{U} / \mathbf{m L})$ \\
\hline Inoculum size $(\mathbf{g} / \mathbf{L})$ & $142.9 \pm 5.09$ \\
1 & $256.0 \pm 3.41$ \\
2 & $211.5 \pm 3.77$ \\
3 & $207.2 \pm 6.12$ \\
4 & $180.0 \pm 4.68$ \\
5
\end{tabular}

The production of protease in shaking condition (263.3 $\mathrm{U} / \mathrm{mL}$ ) was better when compared to static cultures $(110.6 \mathrm{U} / \mathrm{mL})$. This was proved in the present study, shaking condition showed maximum protease activity on the 4th day of incubation. In the fermentation of aerobic culture, the oxygen affects the production of enzymes due to the changes in the metabolic pathway and metabolic fluxes [50]. According to Ducros et al.,[51], the respiration rate of the aerobic culture is dependent on the dissolved oxygen. This is due to physiological alteration in cell metabolism [52].

Protease production by Penicillium sp. LCJ228 in optimized and original medium was studied. The optimized medium showed a maximum amount of protease production of $261.5 \mathrm{U} / \mathrm{mL}$ on the 4 th day when compared to the original medium which showed a protease activity of $107.2 \mathrm{U} / \mathrm{mL}$. Nearly, 2.4 fold increases in protease production was observed in optimized conditions.

The steps involved in purification of protease produced by Penicillium sp. LCJ228 are summarized in Table 5. After ammonium sulphate precipitation, the enzyme showed 1.3-fold increase in activity with $146 \mathrm{U} / \mathrm{mg}$ of specific activity of protein and $69 \%$ yield. Muthulakshmi et al.,[49] observed 2-fold purification with $66 \%$ of recovery by ammonium sulphate precipitation of protease from Aspergillus flavus. The molecular weight of the ammonium sulphate protease was determined by SDS-PAGE as $\sim 66$ to $70 \mathrm{kDa}$. The activity of protease was also observed by Zymography. Prominent clearing zone was observed indicating that the gelatin was hydrolyzed by the protease obtained by ammonium sulphate precipitation. The Zymogram also showed the presence of three isoenzymes.

Table 5: Partial purification of protease from Penicillium sp. LCJ228.

\begin{tabular}{cccccc}
\hline $\begin{array}{c}\text { Purification } \\
\text { Steps }\end{array}$ & $\begin{array}{c}\text { Enzyme } \\
\text { activity } \\
(\mathbf{U} / \mathbf{m L})\end{array}$ & $\begin{array}{c}\text { Total } \\
\text { protein }\end{array}$ & $\begin{array}{c}\text { Specific } \\
\text { activity } \\
\text { (U/mg) }\end{array}$ & $\begin{array}{c}\text { Purification } \\
\text { (fold) }\end{array}$ & $\begin{array}{c}\text { Yield } \\
(\%)\end{array}$ \\
\hline $\begin{array}{c}\text { Culture } \\
\text { supernatant }\end{array}$ & 251 & 2.3 & 109 & 1.0 & 100 \\
\hline $\begin{array}{c}\text { Ammonium } \\
\text { sulphate } \\
\text { precipitates } \\
(70 \%)\end{array}$ & 175 & 1.2 & 146 & 1.3 & 69 \\
\hline
\end{tabular}

The performance of protease from Penicillium sp. LCJ228 in the removal of blood stains from fabric was examined. The precipitated protease from Penicillium sp. LCJ228 had the efficiency to remove blood stain completely from the piece of cotton fabric without the aid of any of the detergents (Figure 4). This shows the potential of the enzyme from Penicillium sp. LCJ228 in the removal of blood stains. Hence the enzyme can be used as an additive in detergent to enhance its stain removal. This result is in accordance with the earlier reports which also show efficient digestive properties of protease [53]. The alkaline protease from Penicillium sp. LCJ228 has a potential application role as an additive in the detergent formulation. The detergent compatibility of the alkaline protease also reported in Aspergillus sp. [54]. In the present study, the blood stains were removed in a lesser time when treated with the enzyme.

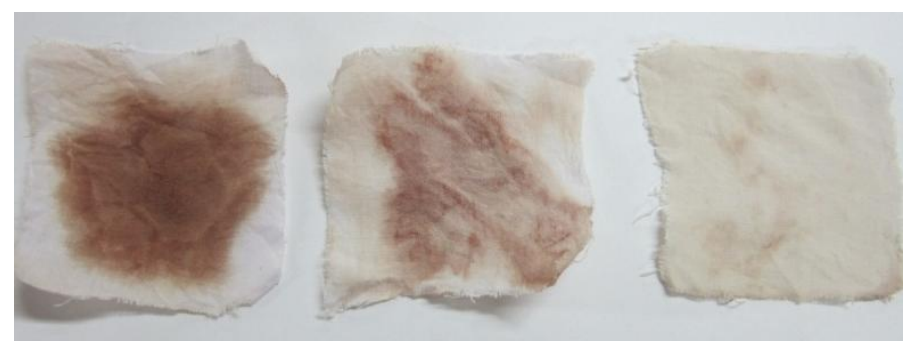

Fig. 4: Removal of blood stains from cotton fabric treated with precipitated protease from Penicillium sp. LCJ228

(a control; b commercial detergent wash; $\mathbf{c}$ treated with precipitated protease)

\section{CONCLUSION}

The present study proved that Penicillium sp. LCJ228 is an efficient protease producer. Optimization of conditions for protease production under submerged fermentation will help in the large scale production of this promising enzyme. The protease from Penicillium sp. LCJ228 also effectively removed blood stains from the cloths than the commercial detergents. Hence the protease from Penicillium sp. LCJ228 can be utilized in detergent industries. However, future studies on molecular identification of Penicillium sp. LCJ228, and purification and characterization of protease from Penicillium sp. LCJ228 would helps to extent its applications in various biotechnological and environmental aspects. 


\section{ACKNOWLEDGMENT}

The authors are thankful to the Management, Loyola College, Chennai for providing necessary facilities and encouragement.

\section{REFERENCES}

1. Shivanand P, Jayaraman G. Production of extracellular protease from halotolerent bacterium Bacillus aguimaris strain VITP4 isolated from kumta coast. Proc Biochem. 2009; 44: 1088-1094.

2. Deng A, Wua J, Zhang Y, Zhang C, Wena T. Purification and characterization of a surfactant -stable high-alkaline protease Bacillus sp. B001. Bioresour Technol. 2010; 101: 7100-7106.

3. Marchand S, Vandriesche G, Cooreviets A, Coudijzer K, Jonghe VD, Dewettinck K. Heterogenisity of heat resistance proteases form milk Pseudomonas sp. Int J Food Microbiol. 2009; 133: 68-77.

4. Ribitscha D, Karla W. Birner-Cruenbergera R, Crubera K. Eiteljoerg I, Remlera P. 2010. C - terminal truncation of a metagenome-derived detergent protease for effective expression in E.coli. J Biotech. 2009; 150: 408-416.

5. Mala B, Rao AM, Deshpande VV. Molecular and biotechnological aspects of microbial proteases. Microbiol Mol Biol Rev. 1998; 62: 597-635.

6. Joo HS, Kumar CG, Park GC, Park SR, Chang CS. Bleach resistant alkaline protease produced by a Bacillus sp isolated from the Korean Polychaete Perriserrula leucophryna. Proc Biochem. 2004; 39:14411447.

7. Mei C, Jiang X. A novel surfactant and oxidation stable alkaline protease from Vibrio metschnikovii Dl-33-51. Proc Biochem. 2005; 40: 2167-2172.

8. Barett AJ. Proteolytic enzymes: serine and cysteine peptidases. Methods Enzymol. 1994; 244:1-15.

9. Madan M, Dhillion S, Singh R. Production of alkaline protease by a UV mutant of Bacillus polymyxa. Indian J Microbiol. 2002; 42:155159.

10. Beg QK, Saxena RK, Gupta R. De-repression and subsequent induction of protease synthesis by Bacillus mojavensis under fed-batch operations. Proc Biochem. 2002; 37: 1103-1109.

11. Fan-Ching Y, Lin IH. Production of acid protease using thin stillage from rice spirit distillery by Aspergillus niger. Enzyme Microb Technol. 1998; 23: 397-402.

12. Oyeleke SB, Egwim EC, Auta SH. Screening of Aspergillus flavus and Aspergillus fumigatus strains for extracellular protease enzyme production. J Microbiol Antimicrob. 2010; 2: 83-87.

13. Gnanadoss JJ, Rebecca R, Jebapriya, GR. Production of protease from Aspergillus niger and Mucor mucedo under submerged and solid state fermentation. Int J Curr Res. 2011; 3(10): 075-078.

14. Farley PC, Ikasari L. Regulation of secretion of Rhizopus oligosporus extra cellular carboxyl proteinases. J Gen Microbiol. 1992; 138: 25392544.

15. Chrzanowska J, Kolaczkowska M, Polanowski A. Production of extracellular proteolytic enzymes by various species of Penicillium. Enzyme Microb Technol. 1993; 15:140-143.

16. Ikram-ul-haq, Mukhtar H, Umber, H. Production of protease by Penicillium chrysogenum through optimization of environmental conditions. J Agri Soc Sci. 2006; 2(1): 23-25.

17. Gnanadoss JJ, Devi SK. Optimization of nutritional and culture conditions for improved protease production by Aspergillus nidulans and Aspergillus flavus. J Microbiol Biotech Food Sci. 2015; 4(6): 518 523.

18. Kumar A, Sachdev A, Balasubramanyan SD, Saxena A, Lata K. Optimization of conditions purification and for production of neutral and alkaline protease characterization of the heat stable serine proteinase from species of Bacillus and Pseudomanas. Ind J Microbiol. 2002;42: 233-236.

19. Kumar CG, Takagi H. Microbial alkaline proteases: From a bioindustrial viewpoint. Biotechnol Adv. 1999; 17: 561-594.
20. Rao MB, Tanksale AM, Ghatge MS, Deshpande VV. Molecular and biotechnological aspects of microbial proteases. Microbiol Mol Biol Rev. 1998; 62: 597-635.

21. Sarker PK, Talukdar SA, Deb P, Sayem SM, Mohsina K. Optimization and partial characterization of culture conditions for the production of alkaline protease from Bacillus licheniformis P003. SpringerPlus. 2013; 2: 506.

22. Pangrikar PP, Wadikarl MS, Borde VU, Chavan AM. Production of protease enzyme from rhizospheric fungi of bt and non bt cotton varieties. Biosci Discovery. 2011; 2 (2): 249 -250.

23. Sayem SMA, Alam MJ, Hoq MM. Effect of temperature, $\mathrm{pH}$ and metal ions on the activity and stability of alkaline protease from novel Bacillus licheniformis MKZ03. Proc Pakistan Acad Sci. 2006; 43(4): 257-262.

24. Karthick R, Namasivayam S, Sivasubramanian S, Ganesh K. Influence of media on protease production by Beauveria bassiana ( Bals.) Vuil. and their stability towards commercially available detergents, surfactants and enzyme inhibitors. Int J Biol Technol. 2010; 1(1): 78 83.

25. Keay L, Wildi BS. Proteases of the genus Bacillus, I. Neutral proteases. J Biotechnol Bioeng. 1970; 12: 179-212.

26. Lowry OH, Roserbrough NJ, Farr AL, Randall R. Protein measurement with Folin Phenol Reagent. J Biol Chem. 1951; 193: 265-275.

27. Beg QK, Gupta R. Purification and characterization of an oxidation stable, Thiol dependent serine protease from Bacillus mojavensis. Enzyme Microbial Technol. 2003; 32: 294-304.

28. Ellaiah P, Srinivasulu B, Adinarayana K. A review on microbial alkaline proteases. J Sci Ind Res. 2002; 61: 690-704.

29. Shridhar P, Deepti A, Panka P, Tushar B. Production of alkaline protease by Penicillium sp. under SSF conditions and its application to soy protein hydrolysis. Proc Biochem. 2003; 39: 977-981.

30. Abirami VS, Menakshi A, Kanthym K, Bhar R, Mahlingm R. Partial purfication and characterization of an extracellular protease from Penicillium janthinelum and Neurospa crassa. Eur J Exp Biol. 2011; 1(3): 114-123.

31. Oskouie SF, Tabandeh F, Yakhchali B, Eftekhar F. Response surface optimization of medium composition for alkaline protease production by Bacillus clausii. J. Biochem. Engineer. 2008; 39: 37-42.

32. Nochure SV, Roberts MF, Demain AI. True cellulase production by Clostridium thermocellum grown on different carbon sources. Biotechnol Lett. 1993; 15: 641-646.

33. Ire FS, Okolo NBN, Moneke AN,Odibo FJC. Influence of cultivation conditions on the production of a protease from Aspergillus carbonarius using submerged fermentation. Afr J Food Sci. 2011; 5 353-365.

34. Varela H, Ferrari MD, Belobradjic L. Effect of medium composition on the production by a new Bacillus subtilis isolate of protease with promising unhairing activity. World J Microbiol Biotechnol. 1996; 12: 643-645.

35. Kumara CG, Tiwarib MP, Janya KD. Novel alkaline serine proteases from alkalophilic Bacillus spp.: purification and some properties. Proc Biochem. 1999; 34(5): 441-449.

36. Chellapandi P. Production and preliminary characterization of alkaline protease from Aspergillus flavus and Aspergillus terreus. E-J Chem. 2010; 7(2): 479-482.

37. Srinubabu G, Lokeswari N, Jayaraju K. Screening of nutritional parameters for the production of protease from Aspergillus oryzae. E-J Chem. 2007; 4(2): 208-215.

38. Tremacoldi CR, Carmona EC. Production of extracellular alkaline proteases by Aspergillus clavatus. World J Microbiol Biotechnol. 2005; $21: 169-172$

39. Wang Y, Lee M. Influence of culture and nutritional condition on the production of protease from Thermophilic strain Aspergillus species NTIJ-FC-671. J Chin Agr Chem Soc. 1996; 34: 732-742.

40. Nehra KS, Dhillon S, Chaudhary K, Singh R. Production of alkaline prlotease by Aspergillus species under submerged and solid state fermentation. Indian J Microbiol. 2002; 42: 43-47. 
41. Chauhan B, Gupta R. Application of statistical experimental design for optimization of alkaline protease production from Bacillus sp. RGR14. Proc Biochem. 2004; 39: 2115-2122.

42. Ashour SA, EL Shore HM, Metwally M, Habib SA. Fungal fermentation of Whey incorporated with certain supplements for the production of protease. Microbios. 1996; 86:59-69.

43. Kirankumar S, Jayashree V, Hanchinalmath Y, Sai S, Debajit B, Prasad T. Optimization and production of alkaline proteases from agro byproducts using a novel Trichoderma Viridiae strain VPG 12, isolated from agro soil. Int Lett Nat Sci. 2014; 9: 77-84.

44. Jenitta XJ, Gnanadoss JJ. Effect of carbon, nitrogen sources and inducers on protease production by Penicillium citrinum LCJ222. Int J Curr Res. 2014. 6(11): 9544-9549.

45. Sandhya C, Sumantha A, Szakacs G, Pandey A. Comparative evaluation of neutral protease production by Aspergillus oryzae in submerged and solid state fermentation. Proc Biochem. 2005; 40: 2689-2694.

46. Paranthaman R, Alagusundaram K, Indhumathi. Production of protease from rice mill wastes by Aspergillus niger in solid state fermentation. World J Agric Sci. 2009; 5(3): 308-312.

47. Palanivel P, Ashokkumar L, Balagunathan R. Production, purification and fibrinolytic characterization of alkaline protease from extremophilic soil fungi. Int J Pharm Bio Sci. 2013; 4(2): (B) 101-110.

48. Coral G, Arikan B, Unaldi MN, Guvenmes H. Purification and characterization of a protease-resistant cellulase from Aspergillus niger. J Fermentation Bioeng. 2002; 39: 122-127.

49. Muthulakshmi CD, Gomathi DG, Kumar G, Ravikumar G, Kalaiselvi M, Uma C. Production, purification and characterization of protease by Aspergillus flavus under solid state fermentation. JJBS 2011; 4: 137-148.

50. Calik P, Calik G, Ozdamar TH. Oxygen transfer effects in serine alkaline protease fermentation by Bacillus licheniformis: Use of citric acid as the carbon source. Enzyme Microb Technol. 1998; 23: 451461.
51. Ducros E, Ferrari M, Pellegrino M, Raspanti C, Bogni C. Effect of aeration and agitation on the protease production by Staphylococcus aureus mutant RC128 in a stirred tank bioreactor. Bioprocess Biosyst Eng. 2009; 32 (1):143-148.

52. Hwang ST, Wachter C, Schatz G. Protein import into the yeast mitochondrial matrix- A new translocation intermediate between the two mitochondrial membranes. J Bio Chem. 1991; 266: 21083-21089.

53. Malathi S, Chakraborty R. Production of alkaline protease by a new Aspergillus flavus isolate under solid substrate fermentation conditions for use as a depilation agent. Appl Environ Microbiol. 1991; 57: 712 16

54. Dubey R, Adhikary S, Kumar J, Sinha N. Isolation, production, purification, assay and characterization of alkaline protease enzyme from Aspergillus niger and its compatibility with commercial detergents. Dev Microbiol Mol Bio. 2010; 1: 75-94.

\section{How to cite this article:}

Benluvankar V, Priya SE and Gnanadoss JJ. Medium Formulation and its optimization for increased protease production by Penicillium sp. LCJ228 and its potential in blood stain removal. J App Biol Biotech. 2016; 4 (01): 020-026. DOI: 10.7324/JABB.2016.40104 